\title{
Anger-provoking events in driving diaries: A content analysis
}

\author{
Wickens, C. M., Roseborough, J. E. W., \\ Hall, A., \& Wiesenthal, D. L.
}

Version Post-Print/Accepted Manuscript

Citation Wickens, C. M., Roseborough, J. E. W., Hall, A., \& Wiesenthal, D. L. (published version) (2013). Anger-provoking events in driving diaries: A content analysis. Transportation Research Part F, 19, 108-120.

\section{Copyright / License (c) () $\ominus$}

This work is licensed under a Creative Commons AttributionNonCommercial-NoDerivatives 4.0 International License.

Publisher's Statement The final publication is available at Elsevier via http://dx.doi.org/10.1016/j.trf.2013.02.002. 
Running head: ANGER-PROVOKING EVENTS IN DRIVING DIARIES

\title{
Anger-Provoking Events in Driving Diaries: A Content Analysis
}

\author{
Christine M. Wickens ${ }^{1}$, James E. W. Roseborough², Ashley Hall ${ }^{3}$, \\ \& David L. Wiesenthal ${ }^{2}$ \\ ${ }^{1}$ Centre for Addiction and Mental Health, Toronto, Ontario, Canada \\ ${ }^{2}$ York University, Toronto, Ontario, Canada \\ ${ }^{3}$ University of Manitoba, Winnipeg, Manitoba, Canada
}

\author{
Correspondence concerning this article should be addressed to: \\ Dr. Christine M. Wickens \\ Centre for Addiction and Mental Health \\ Social and Epidemiological Research Department \\ 33 Russell Street, T417 \\ Toronto, Ontario M5S 2S1 \\ Canada \\ Email: christine.wickens@ camh.ca \\ Telephone: (416) 535-8501 ext. 4711 \\ Fax: (416) 595-6899
}




\begin{abstract}
A previously validated coding scheme of offensive driver behaviour was used to content analyse driving diary entries. A new perceived causation coding scheme was also developed to identify victims' perceptions of why events occurred. Inter-rater reliability of the behaviour coding scheme was very good (kappa $=.81)$. The most frequently reported driver behaviours were weaving and cutting, which was included in $33 \%$ of all diary entries, followed by slow driving (20\%), speeding (13\%), perceived hostile driver displays (13\%), and tailgating (11\%). These results were contrasted with those of the previous applications of the coding scheme. Assessed independently across all diary entries, inter-rater reliability of the coding of three causation categories was within an acceptable range (kappa $=.51, .41, .67$ for retaliation, time urgency, and negligence, respectively). When applied exclusively to the critical diary entries identified by each participant as the most negative and upsetting, the reliability improved greatly (kappa $=.60$, .80 , and .81 ). The most frequently reported source of perceived causation was negligence, involved in $15 \%$ of all diary entries and $41 \%$ of critical events, followed by time urgency ( $14 \%$ of all entries and $29 \%$ of critical events) and retaliation (9\% of all entries and $11 \%$ of critical events). Future research applications of the content coding systems and implications of the findings for driver safety are discussed.
\end{abstract}

Keywords: Driver anger, driver aggression, content analysis, driving diaries 


\section{Introduction}

\subsection{Driver anger and aggression}

Driver anger is a principal precursor to roadway aggression, and thus a significant threat to driver safety (Roseborough, Wiesenthal, Flett, \& Cribbie, 2011; Wickens, Wiesenthal, Flora, \& Flett, 2011). A meta-analysis of 28 studies reported an average correlation of .40 between anger and aggressive driving (Nesbit, Conger, \& Conger, 2007). Given that more than half of all fatal crashes in the United States from 2003 through 2007 involved at least one driver who had committed a potentially-aggressive action (AAA Foundation for Traffic Safety, 2009), it is fair to say that driver anger is frequent and has significant and detrimental consequences for motorists.

\subsection{Research methods in the assessment of driver anger}

Several research initiatives have been undertaken to identify the types of objectionable roadway behaviours that are related to driver anger. These research efforts have adopted a wide variety of predominantly quantitative methodologies including questionnaire studies (e.g., Hennessy \& Wiesenthal, 2001), large-scale telephone surveys conducted by national organisations (e.g., the Traffic Injury Research Foundation; Vanlaar, Simpson, Mayhew, \& Robertson, 2007), field experimentation (e.g., drivers assess their level of stress in situ over a cellular telephone during their roadway journey; Hennessy \& Wiesenthal, 2001; Wickens \& Wiesenthal, 2005), and driving diaries (i.e., drivers record and rate anger-provoking incidents or altercations experienced during regular commuting over a set period of time; Underwood, Chapman, Wright, \& Crundall, 1999; Wickens, Wiesenthal et al., 2011)

\subsection{Content analysis}

Content analysis is a qualitative research methodology that derives inferences by “systematically and objectively identifying specific characteristics of messages" (Whitley, 1996, 
p.385). This methodology has generally been applied to letters, speeches, news reports, and pictorial content. Recently, content analysis has been used to understand sources of driver anger. In a driving diary study, Underwood and colleagues (1999) equipped British drivers with microcassette recorders and asked them to record a diary entry after every car journey taken over a 2-week period. Based on the demonstrated relationship between aggression and accident involvement, Underwood et al. used a five-category collision coding scheme to determine which types of near collisions were more frequently associated with anger. The frequency of anger was greater following incidents where the respondent's vehicle was the object of a near collision by another vehicle versus those where the respondent's vehicle collided into something else. In another diary study, Neighbors, Vietor, and Knee (2002) asked students from a university in the southwestern United States to complete a diary record after every occurrence of driver anger over a 10-day period. Drivers, themselves, were asked to classify the anger-provoking event according to an eight-category coding scheme. More than $59 \%$ of events were coded as being the result of discourtesy, and more than $43 \%$ were the result of dangerous driving by another motorist.

Wickens, Wiesenthal, and Rippey (2005) developed a more detailed ten-category coding scheme to content-analyse telephone complaints of improper driver behaviour received by the Ontario Provincial Police (OPP). Results of the analysis indicated that the most frequently reported complaints involved dangerous lane changes/improper lane usage, speeding, and tailgating. Two interpretations of the results are possible: it may be that these were the most frequently occurring offensive driver behaviours, or that they were perceived as the most offensive and thus warranted reporting to the authorities. The latter interpretation suggests that 
drivers experience a sense of discomfort when their ability to predict the behaviour of other motorists is threatened by violations of crucial driving norms.

Wickens, Wiesenthal, Hall, and Roseborough (2013) revised the ten-category coding scheme for application to online postings to a website soliciting drivers' complaints about other motorists. RoadRagers.com asks visitors to the site to provide details of roadway events involving alleged "bad drivers", including what transpired, where and when it took place, and the make, model, colour, and licence plate number of the offending vehicle. Results of this content analysis revealed that the most frequently reported driver behaviours were cutting/weaving, speeding, perceived displays of hostility, and tailgating. Reports were most frequent on weekdays and during the morning and afternoon rush hour. The study of online complaints replicated several findings from the analysis of telephone complaints reported to the OPP, but possible differences in the sample and data collection method also produced some differences in findings.

These studies demonstrate the value of content analysis to the study of driver anger and aggression that has previously been dominated by quantitative research. Content analysis provides a qualitative perspective, and contributes to a more well-rounded multi-method approach to the topic. Moreover, unlike closed-ended rating scales of driver anger (e.g., Driving Anger Scale; Deffenbacher, Oetting, \& Lynch, 1994), content analysis allows researchers to utilize existing databases, whether created by police agencies or developed on websites, to study objectionable behaviours over different time periods, regions, and countries. As well, with only limited prior research examining the application of attributional theory to driver behaviour (Lennon \& Watson, 2011; Wickens, Wiesenthal, et al., 2011), a coding scheme to contentanalyse open-ended reports of driver attributions would be highly beneficial. 


\subsection{Purpose of the current study}

The purpose of the current study was twofold. First, the study applied the previously developed ten-category offensive driver behaviour coding scheme (Wickens et al., 2005, 2013) to a previously untested dataset: driving diaries. Second, the study tested the reliability of a new coding scheme developed to characterise perceptions of why the offensive driver behaviours occurred.

\section{Method}

Wickens, Wiesenthal, et al. (2011) conducted a driving diary study to examine the applicability of attributional theory to the driving environment. The current study utilised this existing dataset of diaries to further validate the offensive driver behaviour coding scheme developed by Wickens and colleagues.

\subsection{Participants}

Fifty participants were recruited through advertisements posted across a Canadian university campus. An additional 152 participants were recruited through an undergraduate participant pool. Of the 202 total participants who were involved in the study, two respondents were eliminated for careless responding and one respondent was eliminated because he had previously participated in a similar study that might result in biased responding. The remaining sample consisted of 58 males and 141 females, with a mean age of 23.2 years $(S D=7.17)$. In order to participate in the study, all respondents were required to have Internet access from home, drive at least 4 days per week on average, and have held a class $\mathrm{G}$ (licence to drive a standard passenger vehicle) or G2 (the level of graduated licensing at which new drivers are permitted to drive independently) Ontario driver's licence for at least 1 year. Participants reported having possessed a driver's licence for a mean of 6.0 years $(S D=5.74)$. 


\subsection{Measures and procedures}

A full description of the measures and procedures of this study is provided by Wickens, Wiesenthal, et al. (2011). Only those aspects of the study that are relevant to the current analysis will be discussed here.

\subsubsection{Driving diaries}

Participants completed four online driving diaries, once every 2 days. Participants received emails containing a link to the online diary, which asked them to describe a negative driving event involving another motorist that was experienced during the previous $48 \mathrm{~h}$. Participants were asked to describe the nature of the event, where it took place, how the encounter made them feel, and what they did after or in response to the event. Participants also used a 7-point Likert-type scale to rate the negativity and severity of the event and the extent to which they felt anger toward the other driver. Participants were instructed to submit their diary entry but to respond with "not applicable" to all open-ended questions and " 1 " to all scales if they had not driven in the past $48 \mathrm{~h}$, or if they had not experienced even a minor annoyance on the roadway. Participants who did not submit their diary entry on time received a prompting email each morning thereafter.

\subsubsection{Critical incident description and perceived cause}

Following completion of the four diary entries, participants were asked to respond to a final online survey focused on the most upsetting and negative event previously reported in their driving diaries. This 'critical event' was selected based on the diary with the highest Likert-type rating of anger toward the other driver. If multiple entries had the same score on the anger scale, the diary with the highest negativity rating was selected. If multiple entries had identical scores on both the anger and negativity scales, the diary with the highest severity rating was selected. 
The first question of the online survey asked participants to write a short paragraph describing again the critical incident. The second question asked participants to identify the cause of the incident; why did the event occur?

\subsubsection{Offensive driver behaviour coding scheme}

The offensive driver behaviour coding scheme (Wickens et al., 2005, 2013) was adapted for use in the current study. Minor revisions to the coding scheme were made, predominantly in the examples provided to coders. The full coding scheme and coding instructions can be obtained from the authors. A listing of the 11 main categories and several sub-categories, along with abbreviated definitions, are provided in Table 1.

\section{INSERT TABLE 1 HERE}

All diary entries were coded by two primary coders (a postdoctoral fellow and a graduate student, both of whom were experienced coders). Each diary entry could be classified as falling into one or more categories (or sub-categories). For example, in describing their upsetting driving event, one respondent wrote:

I was driving on the 401, and someone was tailgating me on the highway and I was already exceeding the speed limit a bit, so I didnt $[$ sic $]$ want to go faster. Then there was a bit of traffic so I had to break [sic], and the car behind me had to break [sic] suddenly and I could see her yelling at me through my mirror. So she switched lanes, and I noticed she was tailgating the other car as well [sic].

This diary entry was classified as speeding/racing (Ai), tailgating (B), and perceived hostile driver display $(\mathrm{Hi})$. If the two primary coders were unable to reach agreement on at least one possible classification of a diary entry, a third independent coder (an experienced graduate student) categorised the diary entry. The final classification included categories selected by at 
least two of the three coders. Upon completion of all coding, the three coders met to discuss and come to an agreement on the classification of diary entries where at least one category was not selected by two of the three coders.

\subsubsection{Perceived cause of the offensive behaviour coding scheme}

A second coding scheme was developed to examine possible causes identified by the participants for the offending driver's behaviour. Based on a preliminary review of the diary data, as well as possible causes of driver stress and aggression identified in previous studies (e.g., Lennon \& Watson, 2011; Roseborough et al., 2011; Wickens \& Wiesenthal, 2005), three categories were included in this initial piloting of the coding scheme: retaliation for a perceived offence, time urgency, and negligence. Table 2 provides the definitions for each of these categories. Again, the full coding scheme, including instructions to coders, can be obtained from the authors.

\section{INSERT TABLE 2 HERE}

All diary entries were coded by two primary coders. Each diary entry could be classified as indicating the presence or absence of each perceived cause. If the two primary coders were unable to reach agreement on the categorisation of a diary entry, a third independent coder broke the tie. Diary entries whose behavioural classification could not be determined (was classified as K) were not coded for perceived causation.

The diary entry questions did not specifically ask participants to identify the perceived cause of the negative driving event reported, as this question being asked prematurely may have interfered with the original purpose of the Wickens, Wiesenthal, et al. (2011) study. However, the first two questions of the subsequent online survey concerning the most negative and upsetting driving event asked participants to describe the critical incident again and to identify its 
possible cause. Therefore, the perceived cause coding scheme was applied twice. The first time, it was applied to any spontaneous mentioning of causes included in the original diary entries. The second time, it was applied to the original diary entry, the descriptive paragraph, and the identified possible causes provided for the critical event diaries only.

\section{Results}

In submitting their first diary entry, nine respondents indicated that they had not encountered a negative driving event involving another motorist. These numbers increased to 13 , 42, and 35 participants for the second, third, and fourth diary entries. In some cases, respondents had reported events that did not involve another motorist (e.g., they involved a cyclist, they reported the participant's own behaviour). An additional 8 diary entries were not subject to content coding for these reasons. Therefore, across all four diary entries, approximately $86.6 \%$ of respondents reported at least a minor anger-provoking event involving another motorist within a 48-h period.

\subsection{Classification of behaviours}

The reliability of the offensive behaviour coding scheme across the remaining 689 diary entries was very good (kappa $=.81$; Altman, 1991 as cited in Shin, Hallett, Chipman, Tator, \& Granton, 2005). The three coders could not reach an agreement on the classification of just 7 complaints, approximately $1 \%$ of the total sample. These reports were discussed and coded by the three coders as a group.

As can be seen in Figure 1, the most frequently reported driver behaviour was weaving and cutting, which was included in $32.7 \%$ of all diary entries. This was followed by slow driving (19.9\% of all diary entries), speeding (13.4\% of all diary entries), perceived hostile driver displays (13.1\% of all diary entries), and tailgating (10.7\% of all diary entries). As they would not be visible in the figure, Table 3 provides Wilson score confidence intervals (without 
continuity correction) for the proportions presented in Fig. 1.

\section{INSERT FIGURE 1 AND TABLE 3 HERE}

In order to characterise the types of behaviours identified as the most anger-provoking, the classification of offensive driver behaviours can be further subdivided into: (a) those diary entries that were identified as the most negative and upsetting (i.e., the critical events) based on Likert-type ratings of anger provocation, negativity, and severity, and (b) those that were not as offensive (i.e., the non-critical events). Fig. 2 presents the behavioural classification of critical versus non-critical events as a percentage of the relevant diary entries (Wilson score confidence intervals without continuity correction are included in Table 3). Critical incidents were not identified for two participants because they identified entirely new events for the final online survey. When examining the critical events, the most frequently reported driver behaviours were weaving and cutting (40.1\% of critical diary entries), improper lane usage (14.7\% of critical diary entries), slow driving (12.7\% of critical diary entries), speeding, tailgating, and violating traffic signs and signals (each involving $11.2 \%$ of critical diary entries).

\section{INSERT FIGURE 2 HERE}

As diary entries sometimes reported more than a single offensive behaviour, an examination of which independent offensive behaviours were associated with the highest ratings of anger is not a straightforward task. Diary entries that were coded as containing more than one type of offensive behaviour received higher average ratings of anger $(M=4.69, S D=1.55)$ than those diary entries that were coded as containing a single type of offensive behaviour $(M=4.35$, $S D=1.76, t(453.52)=2.51, p=.01)$. Table 4 provides an orthogonal breakdown of the anger ratings associated with behaviours from single-category diary entries, as well as a nonorthogonal breakdown of the anger ratings of all behaviours including those from multiple- 
category diary entries. The lowest average anger rating was associated with reports of improperly equipped or unsafe vehicles, not including those without headlights (Dii). This was the case for both single-category and multiple-category diary entries. The highest average anger rating varied based on single- versus multiple-category diary entries. In the case of the former, perceived violent driver displays were associated with the highest anger rating, but this was based on just one instance of the behaviour. In the case of multiple-category diary entries, sporadic speeds, erratic/improper braking, and perceived violent driver displays shared the highest average anger rating, but again these averages were based on only a few instances of the behaviour.

\section{INSERT TABLE 4 HERE}

\subsection{Classification of perceived causes}

Fifteen diary entries were deleted from the perceived causation coding exercise because they were categorized as 'K-not classified' in the behavioural coding listed in Table 1. Therefore, a total of 674 diary entries were assessed for spontaneous mentioning of perceived causation. As this was the first piloting of the perceived causation coding scheme, reliability was assessed for each of the three categories of possible causation individually, in order to allow for identification of potential category definitions in need of improvement. Using Altman's ratings (see Shin et al., 2005), the reliability of the time urgency and retaliation coding was moderate (kappa $=.41$ and .51 , respectively). The reliability of the negligence coding was good (kappa $=.67)$.

As can be seen in Fig. 3, the most frequently reported source of perceived causation was negligence, involved in $15.3 \%$ of all coded diary entries. Time urgency was spontaneously mentioned in $13.8 \%$ of diary entries and retaliation was spontaneously mentioned in $8.9 \%$ of diary entries. Wilson score confidence intervals without continuity correction are presented in Table 5 . 


\section{INSERT FIGURE 3 AND TABLE 5 HERE}

The perceived causation coding scheme was applied a second time to the critical events only, for which participants were also asked to write a short paragraph about the incident and to identify its cause. One critical event was not coded for perceived causation because it had been coded as 'K-not classified' in the behavioural coding, and two critical incidents were deleted because they described events that were not among the original diary entries (i.e., they described events that had occurred after the four original diary entries had been submitted). Therefore, a total of 196 critical events were assessed using the perceived causation coding scheme.

When examining the additional information provided for the critical events, the reliability of the perceived causation coding scheme improved greatly. The reliability of the retaliation coding increased but remained within the moderate range of Altman's ratings (kappa $=.60$; see Shin et al., 2005). The reliability of time urgency was good $(k a p p a=.80)$ and the reliability of negligence was very good $(k a p p a=.81)$. In addition, a greater percentage of diary entries were classified as containing references to one of the three perceived causation categories. As can also be seen in Fig. 3, 40.8\% of critical events referenced negligence, $28.6 \%$ referenced time urgency, and $11.2 \%$ referenced retaliation. Wilson score confidence intervals without continuity correction are included in Table 5.

As diary entries sometimes reported more than a single offensive behaviour, it is not possible to examine which perceived causes were associated with each independent behaviour. However, Table 6 provides a non-orthogonal breakdown of the percentage of each behaviour contained in the critical events that cited each of the perceived causes. Reports of weaving and cutting, improper lane usage, excessively slow driving, failing to signal turns, disobedience of traffic signs and signals, blocking, and use of a cell phone while driving were most commonly 
perceived to be the result of negligence. Reports of speeding and tailgating were most often associated with time urgency, whereas hostile driver displays were most often associated with retaliation for a perceived driving offense.

\section{INSERT TABLE 6 HERE}

\subsection{Violation of independence}

To this point, the data analyses used the total number of diary entries as the unit of measurement. However, because the original study (Wickens, Wiesenthal, et al., 2011) opted to recruit only 202 participants who contributed up to four diary entries each, using the total number of diary entries as the unit of measurement results in a violation of the assumption of independence. This is a potentially serious limitation, as the personal biases of any given participant may unduly influence the final results.

In response to this concern, an analysis was conducted using the participant as the unit of measurement. Specifically, all diary entries from each participant were compiled to create a single categorisation of the participant rather than a categorisation for each of his/her diary entries. For instance, in the case of the behaviour coding, if the respondent had submitted two diary entries about weaving (Cii), one entry about speeding and tailgating (Ai, B), and one entry about erratic braking (F), the respondent would have been coded as Ai, B, Cii, and F.

As can be seen in Fig. 4, the pattern of behavioural coding using the participants as the unit of measurement is virtually identical to the pattern of behavioural coding using the diary entries as the unit of measurement (Fig. 1). The same can be said for the pattern of coding for perceived causes (see Fig. 5; Wilson score confidence intervals without continuity correction for Fig. 4 and 5 are included in Tables 3 and 5, respectively). These results suggest that the violation of independence did not significantly bias the findings. 


\section{INSERT FIGURES 4 AND 5 HERE}

\section{Discussion}

\subsection{Offensive driver behaviours}

The most frequently reported driver behaviours across all diary entries were weaving and cutting (33\% of all diary entries), slow driving (20\%), speeding (13\%), perceived hostile driver displays (13\%), and tailgating (11\%). This pattern of results is generally consistent with the content analyses of the RoadRagers.com website (Wickens et al., 2013) and the complaints submitted to the OPP Call Centre (Wickens et al., 2005) in which weaving and cutting, speeding, and tailgating were also among the most frequently reported driver behaviours (see Table 7).

\section{INSERT TABLE 7 HERE}

Interestingly, a comparison of the behavioural classification of critical versus non-critical events reveals a difference in the percentage of incidents involving each type of driver behaviour. For instance, weaving and cutting was involved in $40 \%$ of critical events but only $30 \%$ of non-critical events. These results suggest that not only is weaving and cutting the most frequently reported driver behaviour, but it is likely also one of the most offensive driver behaviours. Likewise, improper lane usage was involved in $15 \%$ of critical events but only $7 \%$ of non-critical events. Therefore, although improper lane usage may be somewhat infrequent, it represents a significant source of frustration and anger. These behaviours may be particularly anger-provoking because they violate fundamental driving norms and reduce drivers' ability to predict the behaviour of other motorists. These behaviours may also be more frequently associated with 'near-miss' situations, where a collision is narrowly avoided. Near-misses are often followed by driver anger, particularly when a driver does not play an active role in the near collision or when the driver does not perceive him/herself as being at fault for the incident 
(Underwood et al., 1999). In examining the average anger scores associated with each category of behaviour, both the highest and lowest anger ratings were associated with infrequently reported behaviours. Although probability theory would caution against drawing conclusions based on low frequency data, it may be that some of the least frequent events are also the most anger-provoking (e.g., perceived violent driver display).

The greatest difference in the classification of complaints between the OPP dataset and the RoadRagers.com dataset was the percentage of complaints involving perceived displays of driver hostility. In the OPP study (Wickens et al., 2005), only 6\% of complaints involved perceived hostile/violent driver displays. In the RoadRagers.com study, driver hostility and driver violence were divided into two separate categories, and still, perceived driver hostility was involved in $25 \%$ of reports. Wickens et al. (2013) speculated that the greater number of reported cases of driver hostility reported online was a function of how each of the datasets was collected. In the case of the OPP data, perceived driver hostility was likely screened out of the reports by the OPP Call Centre personnel, as obscene gestures or unkind language are not illegal. This practice would have resulted in an underestimation of the frequency of hostile driver displays. It was also speculated that in the case of the RoadRagers.com data, the name of the website may have overestimated the reported frequency of hostile and violent driver displays by specifically soliciting reports of hostile or aggressive roadway behaviour. Results of the current study add credibility to both of these explanations. At $13 \%$ of all diary entries, the frequency of perceived driver hostility was greater than that reported in the OPP study, but less than that reported in the RoadRagers.com study. Still, its ranking among the top five behaviours noted in the diary entries suggests that perceived driver hostility is a significant source of driver anger.

The frequency of slow drivers represented the greatest difference in the classification of 
driving diary entries. Unlike the previous content analyses, the current study identified slow driving as one of the most frequently reported upsetting driver behaviours. In the OPP dataset, only $1.4 \%$ of complaints involved a slow driver, and in the RoadRagers.com dataset, only $3.8 \%$ of complaints did so. Again, how each dataset was collected likely played a role in this discrepancy. The diary methodology asks participants to identify a negative or upsetting event involving another driver. If participants did not encounter an anger-provoking event on the roadway, they may have felt pressured to report any source of frustration. Thus, this methodology may have provided a more accurate measure of how frequently motorists encounter a frustrating slow driver. Neither of the other methodologies would likely have solicited this type of information. Although it is against the law in Ontario to block or impede the normal and reasonable movement of traffic, it is likely that most reports of slow drivers across the three studies involved motorists who were driving at a speed close to the posted limit. For this reason, it is unlikely for perceived slow driving to be reported to police authorities such as the OPP. Likewise, slow driving would not typically be associated with "road rage", unless it involved blocking a fellow motorist from passing (which is covered by the blocking category in the coding scheme). Thus, it is unlikely that complaints of slow driving would be posted to the RoadRagers.com website. Therefore, the current study suggests that slow drivers may be a more frequent source of frustration than previous studies have suggested; however, slow driving is likely not the source of the most intense driving-related anger. A review of the behavioural classification of critical versus non-critical events in the diary study provides further confirmation of this conclusion. While $23 \%$ of non-critical diary entries involved a slow driver, only $13 \%$ of critical events did so.

It should also be noted that none of the complaints was coded as a hazardous road 
condition that was not attributable to driver behaviour $(\mathrm{J})$. Thus, this category has not been included in any of the figures. Reports of roadway hazards were germane to the study of OPP complaints; however, as participants in the current study were instructed to report a negative event involving another driver, this category was unnecessary in the current analysis.

\subsection{Perceived causation}

The new perceived causation coding scheme piloted three possible causes for offensive drivers' behaviours. Assessed separately, the reliability of the coding for all three categories was in an acceptable range for the diary entries alone, but improved greatly when applied to the diary entries plus the additional descriptive information from the online survey. This was expected given that the survey questions asked participants directly about perceived causation. The lowest reliability rating was found for retaliation. Future research should consider revising the definition and instructions for this category in order to further improve its reliability.

Negligence was the most frequently reported cause for offensive driver behaviour overall, and for multiple categories of behaviour including weaving and cutting, improper lane usage, excessively slow driving, failure to signal turns, disobedience of traffic signs and signals, blocking, and use of a cell phone while driving. These results suggest that many motorists assume that other roadway users are less skilled or careful drivers, which is consistent with a large body of research (e.g., Matthews \& Moran, 1986; Svenson, 1981). This overconfidence in one's driving skills is associated with misperceptions of risk in the driving environment, more risky and aggressive driving, and ultimately, increased risk of a motor vehicle collision (Finn \& Bragg, 1986).

The dominance of negligence as a perceived cause of driver behaviour is highly informative for the application of attributional theory to the driving context. Theories of 
attribution describe how we cognitively explain the events around us, and traditionally focus on the causality of behaviours and events (Fincham \& Jaspars, 1980). Attributional models have recently been applied to driver behaviour, but have not often included a direct measure of negligence (e.g., Roseborough et al., 2011, Wickens, Wiesenthal, et al., 2011). For instance, in the study originally publishing the driving diary data, Wickens, Wiesenthal, et al. (2011) found that causal attributions (e.g., perceived controllability of the offensive behaviour) positively predicted the degree to which the victim held the offending driver responsible for his/her behaviour, which was positively associated with anger felt towards the offending driver. Interestingly, this relationship was not as strong for the attribution of intentionality. The authors suggested that for some participants, a lack of intention was perceived as negligence on the part of the offending driver, and that this lack of intention was associated with holding the offending driver responsible for the negative driving event. The fact that the current study identified negligence as a possible cause of nearly $41 \%$ of the critical incidents adds credibility to this interpretation of the original study's findings, and suggests that future attributional studies of driver behaviour should include this perceived source of causation.

Further development of the perceived causation coding scheme will need to include a wider variety of possible causes for offensive driver behaviour. Focus groups and interviews may prove useful for generating a list of possible causes to consider for inclusion in the expanded coding scheme (e.g., Lennon \& Watson, 2011).

\subsection{Limitations}

The primary limitation of this study is that it utilises an existing dataset to further validate an established coding scheme and to pilot a new one. The use of an existing dataset minimised the financial and labour costs associated with conducting this analysis, and the dataset provides a 
new type of data (i.e., driving diary data) to which the behavioural coding scheme had not previously been applied. However, the research questions and statistical analyses included in the current coding study were extremely limited by the design of the original research. For instance, unlike the content analyses of the OPP telephone complaints (Wickens et al., 2005) and the RoadRagers.com online complaints (Wickens et al., 2013), we were unable to assess seasonal, weekly, or temporal patterns in complaint frequency. The use of a convenience sample was also problematic. Participants in the current study were primarily young university students, and certainly not representative of all drivers. However, previous research has shown that aggressive driving perpetration and victimisation are greater among young drivers (Wickens, Mann, Stoduto, Ialomiteanu, \& Smart, 2011).

\subsection{Implications of the research and future directions}

The successful validation of the offensive driver behaviour coding scheme and piloting of the perceived causation coding scheme suggest that these categorisation systems may represent valuable tools for future research projects. Application of the behaviour coding scheme to OPP records (Wickens et al., 2005) provided information concerning daily, weekly, and seasonal variations in risky and aggressive driving behaviour that could be used to more efficiently target problem drivers. Adoption of the coding scheme by multiple jurisdictions would allow for regional comparisons of problem driver behaviour and the identification of environmental variables predictive of the behaviour. For instance, risky and aggressive driving may be more frequent in places with a warmer climate or more prevalent during the summer months in places with a more temperate climate (Wickens et al., 2005, 2013). These coding schemes could also be applied to newspaper articles or television news reports of offensive driver behaviour to determine how the issue is portrayed in the media. Neighbourhood associations could use the 
coding schemes to guide discussion of roadway safety concerns specific to their communities. Focus groups addressing roadway safety, such as those conducted by the National Highway Traffic Safety Administration (1998), could also adopt the coding schemes for systematic interpretation of respondents' commentary. Potential applications of a valid and reliable typology of risky or aggressive driver behaviour are numerous.

An expanded study using both driving diaries and the validated coding schemes would also be beneficial. The current driving diaries dataset responded to existing information gaps (e.g., frequency versus intensity of anger generated by offensive driver behaviours), added credibility to tentative explanations for previous research findings (e.g., intentionality as a contributor to judgments of responsibility for offensive roadway behaviours; Wickens, Wiesenthal, et al., 2011), and recognised patterns of roadway behaviour ignored by previous content analysis research (e.g., the frequency of slow drivers as a source of frustration and annoyance). Nonetheless, as the current study utilised an existing diary database, it was limited in the research questions it could address and the variables it could consider. For instance, respondents' general mood or level of state stress may have played a significant role in the interpretation of all or a select few potentially offensive driver behaviours (Wickens, Mann, \& Wiesenthal, in press; Wiesenthal, Lustman, \& Roseborough, in press). Time urgency may also have affected which behaviours were perceived as anger-provoking (Wickens \& Wiesenthal, 2005). The types of roads where these offensive drivers were encountered, the level of traffic congestion at the time, or how long the respondent was in the vehicle before the anger-provoking event occurred, may also be informative (Underwood et al., 1999). A future diary study using retrospective reporting as in the current study, or in situ reporting via side-of-the-road cellular telephone or text interviews (Wickens \& Wiesenthal, 2005), could include scales and items to 
reflect these additional variables. Demographic characteristics and personality traits may also be relevant to on-road anger provocation (Wickens et al., in press; Wiesenthal et al., in press), and inclusion of relevant measures before diary reporting would allow for consideration of these variables as potential moderators or mediators of driver anger. Results of these proposed studies would have important implications for the types of traffic calming interventions that should be initiated, as well as where and when efforts should be focused.

Results of the three content analyses already conducted using the offensive driver behaviour and perceived causes coding schemes are also relevant to driver education. Teaching novice drivers about how their own behaviours on the roadway can contribute to other drivers' anger and aggression can assist them in avoiding the development of roadway habits that are considered offensive to other motorists. Likewise, understanding drivers' perceptions of the causes for other motorists' offensive behaviours can assist in the development of attribution training programs. Teaching motorists to recognize cognitive biases in explaining their own and others' driver behaviours may help motorists to reduce their anger in response to offensive roadway behaviour (Takaku, 2006). 


\section{Acknowledgements}

Dr. Wickens was supported by Postdoctoral Fellowships from the Social Sciences and Humanities Research Council and the Centre for Addiction and Mental Health. The authors also wish to acknowledge Dr. Robert Cribbie and Dr. Robert Mann for their advice and guidance with the statistical analysis of the data, and various anonymous reviewers for valuable recommendations that greatly improved the manuscript. 


\section{References}

AAA Foundation for Traffic Safety. (2009). Aggressive driving: Research update. Downloaded October 1, 2010 from http://www.aaafoundation.org/pdf/AggressiveDrivingResearchUpdate2009.pdf.

Deffenbacher, J. L, Oetting, E. R., \& Lynch, R. S. (1994). Development of a driving anger scale. Psychological Reports, 74, 83-91.

Fincham, F. D., \& Jaspars, J. M. (1980). Attribution of responsibility: From man the scientist to man as lawyer. In L. Berkowitz (Ed.), Advances in experimental social psychology (Vol. 13), New York, NY: Academic, pp. 81-138.

Finn, P., \& Bragg, B. W. E. (1986). Perception of the risk of an accident by young and older drivers. Accident Analysis and Prevention, 18, 289-298.

Hennessy, D. A., \& Wiesenthal, D. L. (2001). Further validation of the Driving Vengeance Questionnaire. Violence and Victims, 16, 565-573.

Lennon, A., \& Watson, B. (2011). "Teaching them a lesson?" A qualitative exploration of underlying motivations for driver aggression. Accident Analysis and Prevention, 43, 22002208.

Matthews, M. L., \& Moran, A. R. (1986). Age differences in male drivers' perception of accident risk: The role of perceived driving ability. Accident Analysis and Prevention, 18, 299-313.

National Highway Traffic Safety Administration. (1998, April). Capital Beltway update: Beltway user focus groups. Retrieved April 7, 2001, from http://www.nhtsa.dot.gov/people/injury/research/aggressive/final.rpt.html 
Neighbors, C., Vietor, N. A., \& Knee, C. R. (2002). A motivational model of driving anger and aggression. Personality and Social Psychology Bulletin, 28, 324-335.

Nesbit, S. M., Conger, J. C., \& Conger, A. J. (2007). A quantitative review of the relationship between anger and aggressive driving. Aggressive and Violent Behavior, 12, 156-176.

Roseborough, J., Wiesenthal, D. L., Flett, G. L., \& Cribbie, R. A. (2011). The belief in an unjust world and narcissism - The influence of personality on perceptions of injustice, driving anger, and aggressive driving. Proceedings of the $21^{\text {st }}$ Canadian Multidisciplinary Road Safety Conference, Halifax, Nova Scotia, Canada.

Shin, P. C., Hallett, D., Chipman, M. L., Tator, C., \& Granton, J. T. (2005). Unsafe driving in North American automobile commercials. Journal of Public Health, 27, 318-325.

Svenson, O. (1981). Are we all less risky and more skillful than our fellow drivers?. Acta Psychologica, 47, 143-148.

Takaku, S. (2006). Reducing road rage: An application of the dissonance-attribution model of interpersonal forgiveness. Journal of Applied Social Psychology, 36, 2362-2378.

Underwood, G., Chapman, P., Wright, S., \& Crundall, D. (1999). Anger while driving. Transportation Research Part F, 2, 55-68.

Vanlaar, W., Simpson, H., Mayhew, D., \& Robertson, R. (2007). The Road Safety Monitor 2006: Aggressive driving. Retrieved from Traffic Injury Research Foundation website: http://www.tirf.ca/publications/PDF_publications/RSM2006_AggressiveDriving_eng.pdf

Whitley, B. E., Jr. (1996). Principles of research in behavioral science. Toronto: Mayfield Publishing Company. 
Wickens, C. M., Mann, R. E., Stoduto, G., Ialomiteanu, A., \& Smart, R. G. (2011). Age group differences in self-reported road rage perpetration and victimization. Transportation Research Part F, 14, 400-412.

Wickens, C. M., Mann, R. E., \& Wiesenthal, D. L. (in press). Addressing driver aggression: Contributions from psychological science. Current Directions in Psychological Science.

Wickens, C. M., \& Wiesenthal, D. L. (2005). State driver stress as a function of occupational stress, traffic congestion, and trait stress susceptibility. Journal of Applied Biobehavioral Research, 10, 83-97.

Wickens, C. M., Wiesenthal, D. L., Flora, D. B., \& Flett, G. L. (2011). Understanding driver anger and aggression: Attributional theory in the driving environment. Journal of Experimental Psychology: Applied, 17, 354-370.

Wickens, C. M., Wiesenthal, D. L., Hall, A., \& Roseborough, J. E. W. (2013). Driver anger on the information superhighway: A content analysis of online complaints of offensive driver behaviour. Accident Analysis and Prevention, 51, 84-92.

Wickens, C. M., Wiesenthal, D. L., \& Rippey, K. (2005). Motorists' perception of aggressive driving: A comparative analysis of Ontario and California drivers. In D. A. Hennessy \& D. L. Wiesenthal (Eds.), Contemporary Issues in Road User Behavior and Traffic Safety, Hauppauge, NY: Nova Science Publishers, pp. 23-36.

Wiesenthal, D. L., Lustman, M., \& Roseborough, J. (in press). Aggressive driving: Current perspectives in theory and research. In A. Smiley (Ed.), Human factors in traffic safety. Tucson, AZ: Lawyers \& Judges Publishing Company, Inc. 


\section{Table 1}

Offensive driver behaviour coding scheme (abbreviated).

(A) Improper speed

(i) Speeding/racing

(ii) Unnecessary slow driving

(iii) Sporadic speeds

(B) Tailgating

(C) Lane usage

(i) Improper lane usage

(ii) Weaving through traffic/cutting off/sideswiping

(D) Improperly equipped/unsafe vehicle

(i) No turn signal

(ii) All other forms of improperly equipped/unsafe vehicle

(E) Disobedience of traffic signs/signals

(F) Erratic/improper braking

(G) Blocking

(H) Perceived driver displays of hostility or violence

(i) Perceived hostile driver displays

(ii) Perceived violent driver displays

(I) Driver inattention

(i) Cell phone use

(ii) Other or unspecified distraction

(J) Hazardous road conditions not
Speed greater than the posted limit or too high for the current road conditions

Such a slow rate of speed as to impede the normal movement of traffic

Continuously changing or unpredictable speeds

Following a vehicle more closely than is reasonable

Has not driven within a single lane, has passed another vehicle by driving outside a single lane and onto the shoulder of the roadway, or has violated the legally prescribed use of a lane

Has moved from one lane to another or has entered a lane from a side road without due regard for whether that movement can be made safely

Failed to use a flashing light signal for turn or lane change

Has operated a vehicle that is improperly equipped (e.g., improper display of license plate, lack of headlight/tail light) or is in such an unsafe condition as to potentially endanger others (e.g, mechanical error, overloading) Failed to obey a traffic control sign (e.g., red light, yield sign, pedestrian crossing)

Sudden and unnecessary braking without due regard for other vehicles

Preventing other vehicles from merging or passing

E.g., yelling, gesturing, horn honking, flashing high beams

Behavioural displays of discontent that are more intense than verbal commentary or gestures that are not included elsewhere in the coding scheme (e.g., chasing/following, getting out of the vehicle to verbally or physically argue, waving a firearm/blunt instrument/weapon, throwing threatening objects)

Inattention associated with cell phone use

Source of inattention not specified or associated with anything but a cell phone

E.g., people/hitchhikers on the road, disabled/abandoned 
attributable to driver behaviour

(K) Cannot be classified vehicle, debris on the road

Cannot be placed in any of the above categories 


\section{Table 2}

Perceived causation coding scheme (abbreviated).

Dees the complainant suggest that the offending driver is
retaliating for something the complainant or another driver may
have done?
NOTE: The complainant's initial action or that of another
driver may have been accidental or purposeful. The
complainant may or may not know what he/she or the other
driver has done to upset the offending driver. However, it
should be clear from the report that the complainant feels that
either he/she or the other driver is being targeted specifically by
the offending driver.
Does the complainant suggest that the offending driver's
behaviour is motivated by time urgency or a desire to surpass
delays in traffic?
Time Urgency
Does the complainant suggest that the offending driver's
actions are the result of negligence (e.g., not paying attention,
not checking a blind spot, mistaking a three-way stop
intersection for a four-way stop intersection, missing the one-
way sign, not knowing the rules of the road, etc.)?


Table 3

Wilson score confidence intervals (without continuity correction) for proportions presented in Figs. 1, 2, and 4.

\begin{tabular}{|c|c|c|c|c|c|c|c|c|}
\hline \multirow[b]{2}{*}{$\begin{array}{l}\text { Offensive driver } \\
\text { behaviours }\end{array}$} & \multicolumn{2}{|c|}{$\begin{array}{l}\text { All diary entries } \\
(n=689) \\
\text { Fig. } 1\end{array}$} & \multicolumn{2}{|c|}{$\begin{array}{l}\text { Critical diary } \\
\text { entries only } \\
(n=197) \\
\text { Fig. } 2\end{array}$} & \multicolumn{2}{|c|}{$\begin{array}{c}\text { Non-critical } \\
\text { diary entries } \\
\text { only } \\
(n=492) \\
\text { Fig. } 2\end{array}$} & \multicolumn{2}{|c|}{$\begin{array}{c}\text { All participants } \\
(n=199) \\
\text { Fig. } 4\end{array}$} \\
\hline & $\begin{array}{c}\text { Lower } \\
95 \% \\
\text { CI }\end{array}$ & $\begin{array}{c}\text { Higher } \\
95 \% \\
\text { CI }\end{array}$ & $\begin{array}{c}\text { Lower } \\
95 \% \\
\text { CI }\end{array}$ & $\begin{array}{c}\text { Higher } \\
95 \% \\
\text { CI }\end{array}$ & $\begin{array}{c}\text { Lower } \\
95 \% \\
\text { CI }\end{array}$ & $\begin{array}{c}\text { Higher } \\
95 \% \\
\text { CI }\end{array}$ & $\begin{array}{l}\text { Lower } \\
95 \% \\
\text { CI }\end{array}$ & $\begin{array}{c}\text { Higher } \\
95 \% \\
\text { CI }\end{array}$ \\
\hline (Ai) Speeding/racing & 11.0 & 16.1 & 7.5 & 16.3 & 11.4 & 17.6 & 32.7 & 46.1 \\
\hline $\begin{array}{l}\text { (Aii) Unnecessary } \\
\text { slow driving }\end{array}$ & 17.1 & 23.0 & 8.8 & 18.1 & 19.3 & 26.7 & 44.9 & 58.6 \\
\hline $\begin{array}{l}\text { (Aiii) Sporadic } \\
\text { speeds }\end{array}$ & 0.1 & 1.1 & 0 & 0 & 0.1 & 1.5 & 0.3 & 3.6 \\
\hline (B) Tailgating & 8.6 & 13.3 & 7.5 & 16.3 & 8.2 & 13.6 & 27.9 & 41.0 \\
\hline $\begin{array}{l}\text { (Ci) Improper lane } \\
\text { usage }\end{array}$ & 7.3 & 11.7 & 10.5 & 20.3 & 5.2 & 9.7 & 21.0 & 33.2 \\
\hline $\begin{array}{l}\text { (Cii) Weaving } \\
\text { through } \\
\text { traffic/cutting } \\
\text { off/sideswiping }\end{array}$ & 29.3 & 36.3 & 33.5 & 47.1 & 25.8 & 33.9 & 67.9 & 79.9 \\
\hline (Di) No turn signal & 7.3 & 11.7 & 4.3 & 11.6 & 7.8 & 13.2 & 22.8 & 35.3 \\
\hline $\begin{array}{l}\text { (Dii) All other forms } \\
\text { of improperly } \\
\text { equipped/ } \\
\text { unsafe vehicle }\end{array}$ & 0.7 & 2.5 & 0.1 & 2.8 & 0.8 & 3.2 & 2.4 & 8.4 \\
\hline $\begin{array}{l}\text { (E) Disobedience of } \\
\text { traffic signs/signals }\end{array}$ & 7.6 & 12.0 & 7.5 & 16.3 & 6.7 & 11.8 & 24.7 & 37.4 \\
\hline $\begin{array}{l}\text { (F) Erratic/improper } \\
\text { braking }\end{array}$ & 1.6 & 3.9 & 1.7 & 7.2 & 1.1 & 3.7 & 5.4 & 13.3 \\
\hline (G) Blocking & 7.3 & 11.7 & 6.7 & 15.2 & 6.7 & 11.8 & 22.8 & 35.3 \\
\hline $\begin{array}{l}\text { (Hi) Perceived hostile } \\
\text { driver displays }\end{array}$ & 10.8 & 15.8 & 6.7 & 15.2 & 11.4 & 17.6 & 31.7 & 45.1 \\
\hline $\begin{array}{l}\text { (Hii) Perceived } \\
\text { violent driver } \\
\text { displays }\end{array}$ & 0.2 & 1.3 & 0 & 0 & 0.2 & 1.8 & 0.5 & 4.3 \\
\hline (Ii) Cell phone use & 2.4 & 5.1 & 2.8 & 9.1 & 1.7 & 4.7 & 8.2 & 17.3 \\
\hline $\begin{array}{l}\text { (Iii) Other or } \\
\text { unspecified } \\
\text { distraction }\end{array}$ & 0.2 & 1.5 & 0.3 & 3.6 & 0.1 & 1.5 & 0.8 & 5.1 \\
\hline $\begin{array}{l}\text { (K) Cannot be } \\
\text { classified }\end{array}$ & 1.3 & 3.6 & 0.1 & 2.8 & 1.7 & 4.7 & 3.9 & 10.9 \\
\hline
\end{tabular}




\section{Table 4}

Mean anger ratings (and standard deviations) associated with offensive driver behaviours.

\begin{tabular}{lcccccc}
\hline & \multicolumn{3}{c}{$\begin{array}{c}\text { Diary entries coded as a } \\
\text { single category }\end{array}$} & \multicolumn{3}{c}{ All diary entries } \\
\cline { 2 - 7 } Offensive driver behaviour & $n$ & $M$ & $S D$ & $n$ & $M$ & $S D$ \\
\hline (Ai) Speeding/racing & 19 & 4.16 & 1.71 & 92 & 4.42 & 1.65 \\
(Aii) Unnecessary slow driving & 99 & 4.09 & 1.67 & 137 & 4.18 & 1.65 \\
(Aiii) Sporadic speeds & 1 & 5.00 & - & 2 & 5.00 & 0 \\
(B) Tailgating & 30 & 3.80 & 1.69 & 74 & 4.16 & 1.63 \\
(Ci) Improper lane usage & 31 & 4.58 & 1.95 & 64 & 4.89 & 1.73 \\
(Cii) Weaving through traffic/cutting & 120 & 4.66 & 1.72 & 225 & 4.74 & 1.65 \\
$\quad$ off/sideswiping & & & & & & \\
(Di) No turn signal & 14 & 4.14 & 1.23 & 64 & 4.61 & 1.42 \\
(Dii) All other forms of improperly & 6 & 2.67 & 1.21 & 9 & 3.33 & 1.73 \\
$\quad$ equipped/unsafe vehicle & & & & & & \\
(E) Disobedience of traffic & 46 & 4.87 & 1.72 & 66 & 4.89 & 1.69 \\
$\quad$ signs/signals & & & & & & \\
(F) Erratic/improper braking & 9 & 4.67 & 2.00 & 17 & 5.00 & 1.70 \\
(G) Blocking & 46 & 4.59 & 1.72 & 64 & 4.61 & 1.66 \\
(Hi) Perceived hostile driver displays & 39 & 3.82 & 1.93 & 90 & 4.20 & 1.78 \\
(Hii) Perceived violent driver & 1 & 7.00 & - & 3 & 5.00 & 2.00 \\
$\quad$ displays & & & & & & \\
(Ii) Cell phone use & 2 & 6.50 & .71 & 24 & 4.75 & 1.57 \\
(Iii) Other or unspecified distraction & 0 & - & - & 4 & 3.50 & 1.73 \\
(K) Cannot be classified & 15 & 3.73 & 1.75 & 15 & 3.73 & 1.75 \\
\hline
\end{tabular}




\section{Table 5}

Wilson score confidence intervals (without continuity correction) for proportions presented in Figs. 3 and 5.

\begin{tabular}{|c|c|c|c|c|c|c|}
\hline \multirow[b]{2}{*}{$\begin{array}{l}\text { Perceived causes of } \\
\text { offensive driver behaviours }\end{array}$} & \multicolumn{2}{|c|}{$\begin{array}{c}\text { All diary entries } \\
(n=689) \\
\text { Fig. } 3\end{array}$} & \multicolumn{2}{|c|}{$\begin{array}{l}\text { Critical diary } \\
\text { entries only } \\
(n=196) \\
\text { Fig. } 3\end{array}$} & \multicolumn{2}{|c|}{$\begin{array}{c}\text { All participants } \\
(n=199) \\
\text { Fig. } 5\end{array}$} \\
\hline & $\begin{array}{c}\text { Lower } \\
95 \% \\
\text { CI }\end{array}$ & $\begin{array}{c}\text { Higher } \\
95 \% \\
\text { CI }\end{array}$ & $\begin{array}{c}\text { Lower } \\
95 \% \\
\text { CI }\end{array}$ & $\begin{array}{c}\text { Higher } \\
95 \% \\
\text { CI }\end{array}$ & $\begin{array}{c}\text { Lower } \\
95 \% \\
\text { CI }\end{array}$ & $\begin{array}{c}\text { Higher } \\
95 \% \\
\text { CI }\end{array}$ \\
\hline Retaliation & 7.0 & 11.3 & 7.5 & 16.4 & 21.0 & 33.2 \\
\hline Time urgency & 11.4 & 16.6 & 22.7 & 35.3 & 30.8 & 44.1 \\
\hline Negligence & 12.8 & 18.2 & 34.2 & 47.8 & 38.5 & 52.2 \\
\hline
\end{tabular}




\section{Table 6}

Percentage of offensive driver behaviours ${ }^{\mathrm{a}}$ reported in the critical event diary entries $(n=196)$ involving each type of perceived cause.

\begin{tabular}{lcccc}
\hline \multicolumn{1}{c}{ Offensive driver behaviours } & $n$ & Retaliation & Time urgency & Negligence \\
\hline (Ai) Speeding/racing & 22 & 9.1 & 68.2 & 4.5 \\
(Aii) Unnecessary slow driving & 25 & 8.0 & 0 & 24.0 \\
(B) Tailgating & 22 & 18.2 & 68.2 & 0 \\
(Ci) Improper lane usage & 29 & 6.9 & 34.5 & 44.8 \\
(Cii) Weaving through traffic/cutting & 79 & 8.9 & 26.6 & 58.2 \\
off/sideswiping & & & & 78.6 \\
(Di) No turn signal & 14 & 7.1 & 28.6 & 40.9 \\
(E) Disobedience of traffic & 22 & 4.5 & 27.3 & 25.0 \\
signs/signals & & & & 35.0 \\
(G) Blocking & 20 & 15.0 & 15.0 & \\
(Hi) Perceived hostile driver displays & 20 & 85.0 & 55.0 & 0 \\
(Ii) Cell phone use & 10 & 0 & & \\
\hline
\end{tabular}

${ }^{a}$ Behaviours involved in less than ten critical event diary entries are not listed. 


\section{Table 7}

Percentage of driver complaints involving each type of offensive driver behaviour.

\begin{tabular}{|c|c|c|c|}
\hline & $\begin{array}{c}\text { Driving diary } \\
\text { entries } \\
(n=689) \\
\end{array}$ & $\begin{array}{c}\text { RoadRagers.com } \\
\text { complaints }^{\mathrm{a}} \\
(n=5,315) \\
\end{array}$ & $\begin{array}{c}\text { OPP } \\
\text { complaints }^{\mathrm{b}} \\
(n=14,406)\end{array}$ \\
\hline \multicolumn{4}{|l|}{ (A) Improper speed } \\
\hline (i) Speeding/racing & 13.4 & 29.4 & 38.5 \\
\hline (ii) Unnecessary slow driving & 19.9 & 3.8 & 1.4 \\
\hline (iii) Sporadic speeds & 0.3 & $<.01$ & 1.4 \\
\hline (B) Tailgating & 10.7 & 24.1 & 17.6 \\
\hline \multicolumn{4}{|l|}{ (C) Lane usage } \\
\hline (i) Improper lane usage & 9.3 & 13.8 & \\
\hline $\begin{array}{l}\text { (ii) Weaving through traffic/cutting } \\
\text { off/sideswiping }\end{array}$ & 32.7 & 54.3 & $62.3^{\mathrm{c}}$ \\
\hline \multicolumn{4}{|l|}{$\begin{array}{l}\text { (D) Improperly equipped/unsafe } \\
\text { vehicle }\end{array}$} \\
\hline (i) No turn signal & 9.3 & 13.4 & \\
\hline $\begin{array}{l}\text { (ii) All other forms of improperly } \\
\text { equipped/unsafe vehicle }\end{array}$ & 1.3 & 1.8 & $4.4^{\mathrm{c}}$ \\
\hline $\begin{array}{l}\text { (E) Disobedience of traffic } \\
\text { signs/signals }\end{array}$ & 9.6 & 8.8 & 1.0 \\
\hline (F) Erratic/improper braking & 2.5 & 11.8 & \\
\hline (G) Blocking & 9.3 & 8.8 & \\
\hline \multicolumn{4}{|l|}{$\begin{array}{l}\text { (H) Perceived driver displays of } \\
\text { hostility or violence }\end{array}$} \\
\hline (i) Perceived hostile driver displays & 13.1 & 24.9 & $6.2^{\mathrm{c}}$ \\
\hline $\begin{array}{l}\text { (ii) Perceived violent driver } \\
\text { displays }\end{array}$ & 0.4 & 7.9 & \\
\hline \multicolumn{4}{|l|}{ (I) Driver inattention } \\
\hline (i) Cell phone use & 3.5 & 3.6 & $1.6^{\mathrm{c}}$ \\
\hline (ii) Other or unspecified distraction & 0.6 & 1.4 & \\
\hline $\begin{array}{l}\text { (J) Hazardous road conditions not } \\
\text { attributable to driver behaviour }\end{array}$ & 0 & 0 & 1.0 \\
\hline (K) Cannot be classified & 2.2 & 3.3 & 3.6 \\
\hline
\end{tabular}

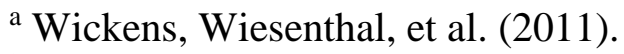

${ }^{\mathrm{b}}$ Wickens et al. (2005).

${ }^{\mathrm{c}}$ Categories were combined in the original version of the coding scheme applied to the OPP complaints dataset. 
Fig. 1. Percentage of diary entries involving each type of driver behaviour $(n=689)$.

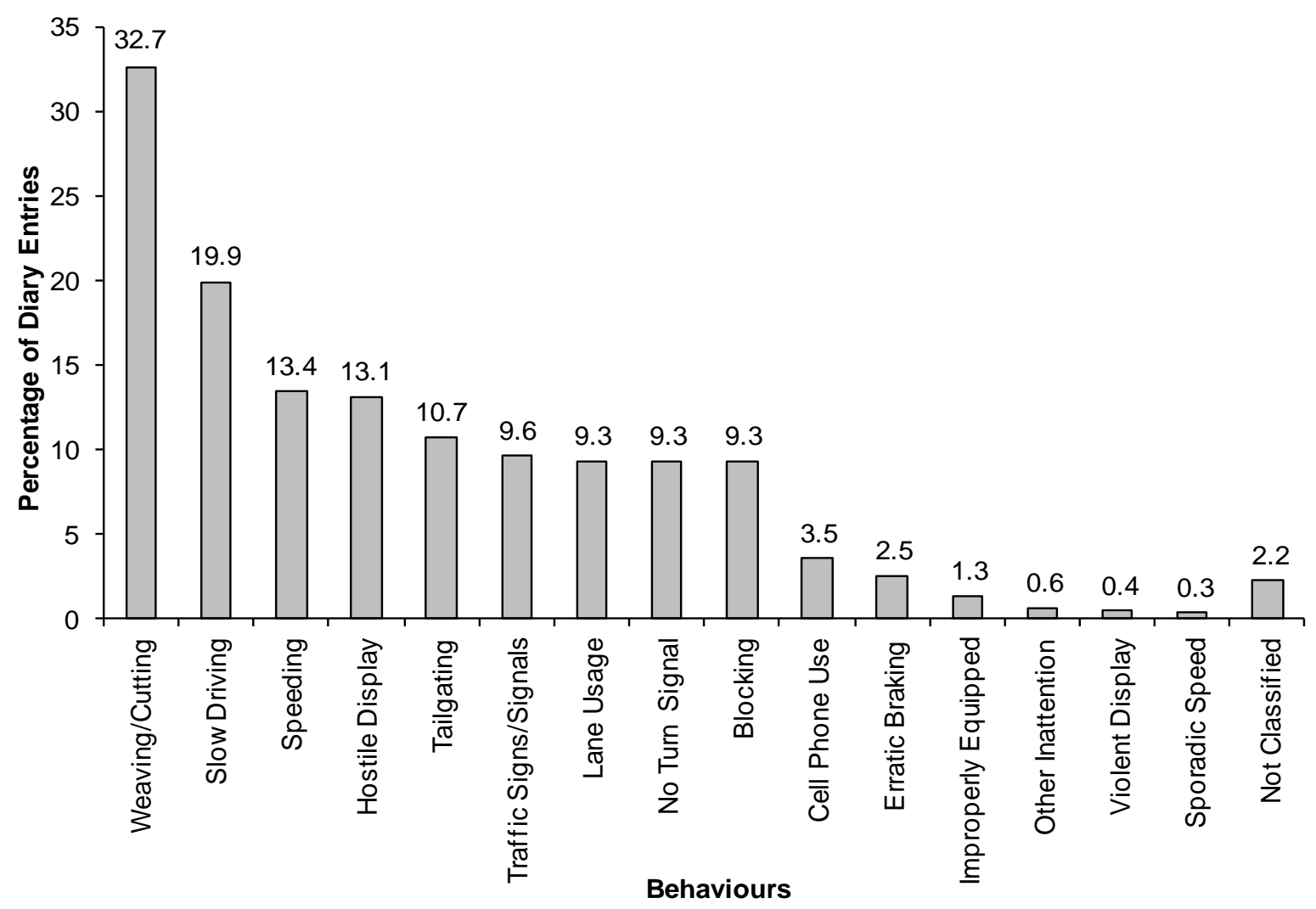


Fig. 2. Percentage of critical $(n=197)$ and non-critical $(n=492)$ event diary entries involving each type of driver behaviour.

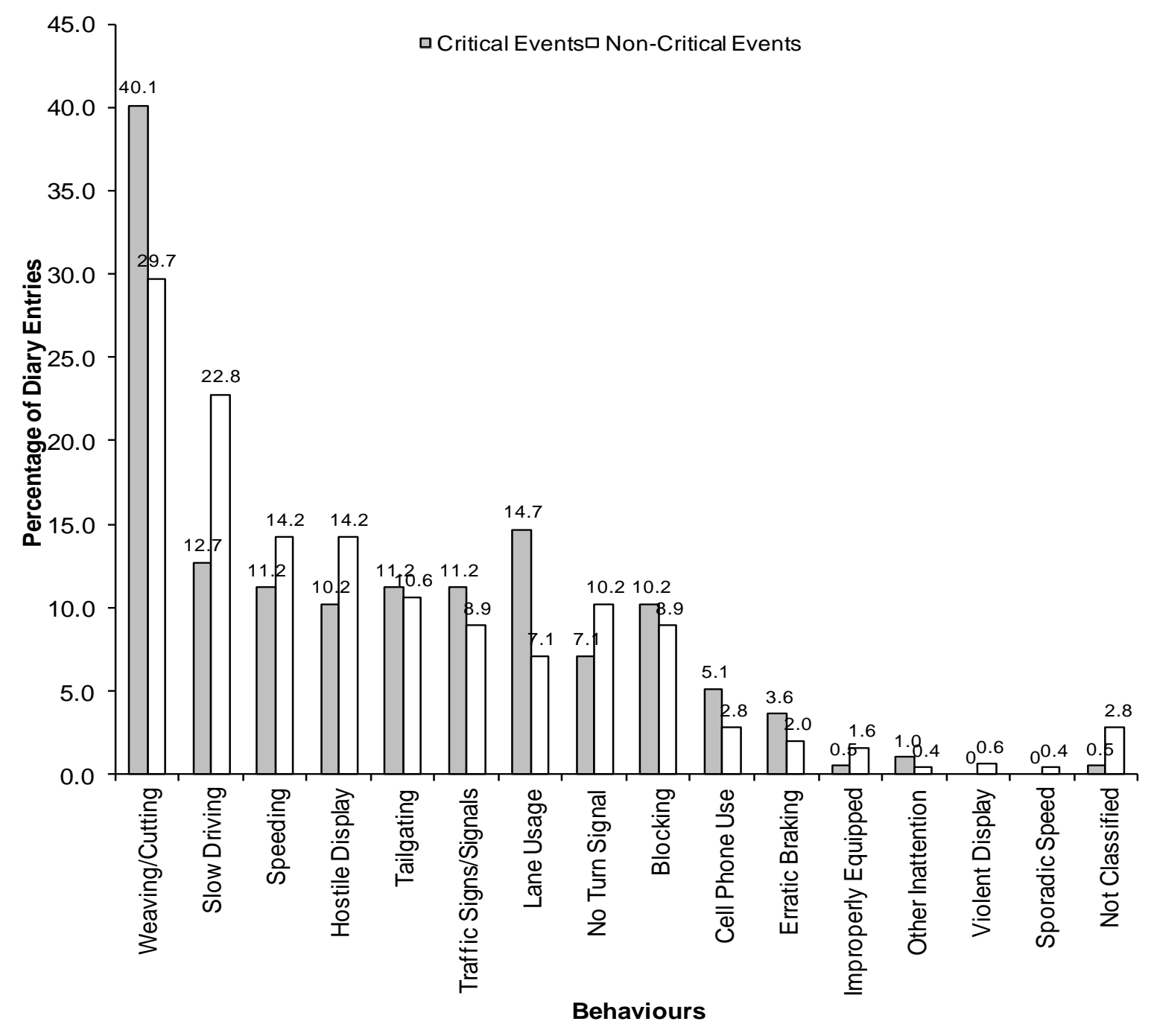


Fig. 3. Percentage of diary entries $(n=674)$ and critical event diary entries (using online survey questions; $n=196$ ) involving each perceived cause.

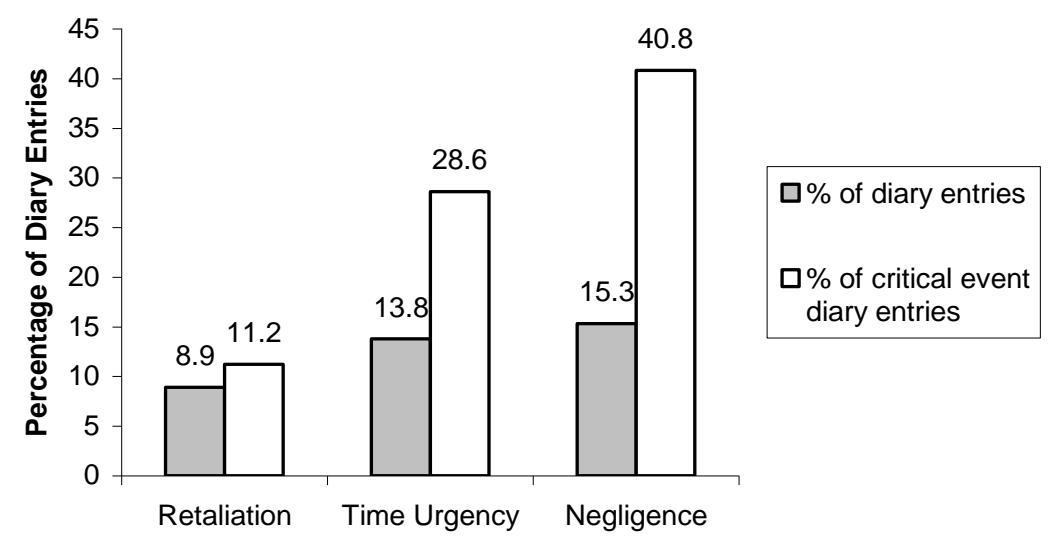


Fig. 4. Percentage of participants reporting each type of driver behaviour $(n=199)$.

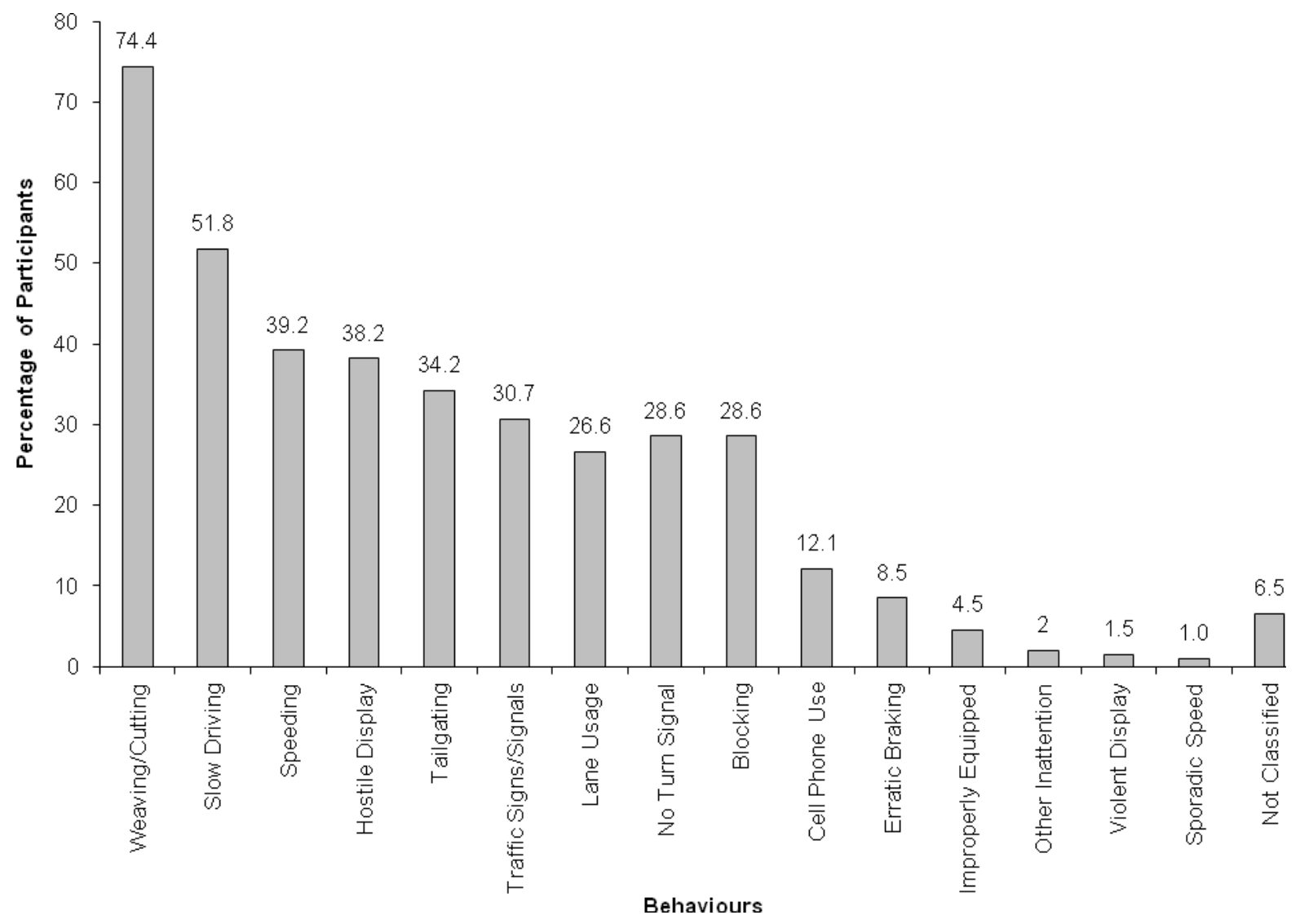


Fig. 5. Percentage of participants reporting each perceived cause $(n=199)$.

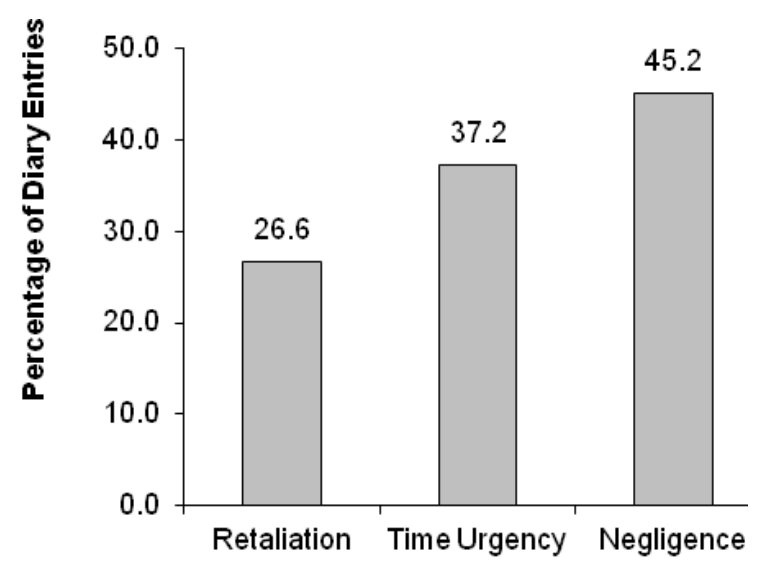

Perceived Causes 